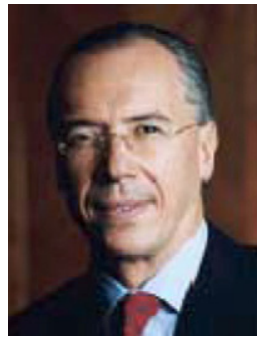

Siegfried Meryn, Editor-in-Chief of jmhg and President of ISMH
Siegfried Meryn, MD President of the International Society of Men's Health and Gender, Medical University of Vienna, Austria

E-mail:

jmhg-eic@ismh.org

\title{
Tackling racial and gender disparities
}

\author{
Siegfried Meryn
}

Despite heightened awareness and interest in racial and gender disparities, changes in health policy to combat these disparities are poor. Little research has been devoted to the role of racism and sexism in our society and their direct contribution to excess morbidity and mortality in our 'Global World'.

In this issue of the jmhg, Young and colleagues [1] address this gap in part with their Overtown Men's Health Study, which examined the health needs of African-American Men. Nearly two-thirds of the men from Overtown who took part reported drinking alcohol, and almost half reported smoking cigarettes. Even more bothersome was the fact that only 33\% reported having a primary care physician or health practitioner, while a remarkable one in four Overtown men sampled reported having been a victim of police violence and nearly two-thirds reported having been incarcerated.

Despite differences in their survey design and methods compared with recent other studies, the results confirmed similarities in the patterns of health behaviours and social experiences within African-American neighbourhoods. Sad enough for the United States, but we should not lose sight of the bigger picture. In today's global world with more immigration than ever before not only the African-American community throughout the USA suffers from poverty, unabated racism, lack of educational and employment opportunities, and un-met health and social services needs! Believe it or not we are facing the exact same problems not only with other minorities within the USA but also throughout most of the member countries of the European Union.
Men's health is still not on any major public health agenda. As Bonhomme [2] points out in this issue of jmhg the health status of men throughout the world has often been considered irrelevant to the wellbeing of other demographic groups, communities or nations. Rightly he states that, in reality, the genders are highly interactive such that their healthoutcomes are intertwined on many levels. This is not an 'either - or' question it is a 'both or neither' issue. Accumulated evidence suggests that a tetrad approach is necessary to optimize community health outcomes, including children's health, women's health, men's health and minority health as coequal partners. Men's health currently receives the least attention of the referenced groups, but failure to address the health needs of any of these groups impairs the ability to fully serve the others.

\section{These changes are all achievable}

Public health politicians on a national and international level should all take part in developing effective activities to overcome racism and sexism, as well as social and gender disparities.

As a further step, let me remind you of the 'Vienna Declaration on the Health of Men and Boys in Europe'.

Signed during the 4th World Congress for Men's Health, on 01 October 2005, this Declaration provides a focus for changes to the way we approach the health of men and boys in Europe and throughout the world. The European Men's Health Forum seeks the support of organisations and individuals in endorsing this Declaration. 
The Vienna Declaration on the Health of Men and Boys in Europe

\section{October 2005}

We, the undersigned, assert that in order to improve public health and prevent disease, there is an urgent need to take specific action to address men's health. In particular, all men must have the opportunity to:

- Achieve the highest possible level of health and well-being.

- Access equitable and affordable healthcare services.

- Receive health advice and information appropriate to their experience and concerns.

Men's use of health services and health information is generally poor across Europe. The delivery of healthcare and information is often not appropriate for men. There is a lack of investment and research in men's health.

Men's life expectancy is unnecessarily low across Europe. Death rates from preventable causes at all ages are unacceptably high. Furthermore, there are significant and avoidable inequalities between countries.

Poor health and premature death in men also affect their families and are an unnecessary burden on health services and the wider economy.

These problems require responses that take account of the specific needs of men.

We therefore call on the EU, national governments, providers of health services and other relevant bodies to:

- Recognise men's health as a distinct and important issue

- Develop a better understanding of men's attitudes to health

- Invest in 'male sensitive' approaches to providing healthcare

- Initiate work on health for boys and young men in school and community settings

- Develop co-ordinated health and social policies that promote men's health.

* Throughout this declaration, the term 'health' includes both physical and mental health.

\section{References}

[1] Young AMW, Perez LM, Northridge ME, Vaughn RL, Braithwaite K, Treadwell HM. Bringing to light the health needs of
African-American men: the Overtown Men's Health Study. jmhg 2007;4: $140-8$.
[2] Bonhomme JJ. Men's health: impact on women, children and society. jmhg 2007; 4:124-30. 